\title{
Bleomycin-Induced Flagellate Erythema
}

\author{
Chun-Ching Luㄹ, Ying-Yi Lu², Qing-Rui Wang ${ }^{3}$, Chieh-Hsin $\mathrm{Wu}^{4}$ \\ ${ }^{1}$ Department of Medicine, National Yang-Ming University Faculty of Medicine, Taipei, Taiwan \\ ${ }^{2}$ Department of Dermatology, Kaohsiung Veterans General Hospital, Kaohsiung, Taiwan \\ ${ }^{3}$ Department of Neurosurgery, Qinghe Central Hospital, Hebei, People's Republic of China \\ ${ }^{4}$ Division of Neurosurgery, Department of Surgery, Kaohsiung Medical University Hospital, Kaohsiung Medical University, Kaohsiung, Taiwan
}

Flagellate erythema, a peculiar cutaneous adverse effect of bleomycin or its derivative peplomycin, occurs in $8-20 \%$ patients during systemic or local therapy (1). It characterised by a linear erythematous streak with hyperpigmentation (2, 3), and was first described by Moulin in 1970 (4). Herein, we present a typical case of flagellate erythema induced by Bleomycin.

A 32 year-old Taiwanese male with mixed germ cell tumour of the anterior mediastinum underwent combination chemotherapy with bleomycin, etoposide, cisplatin (BEP). Seven days after the first cycle of treatment, he developed intensely pruritic erythematous linear papules and plaques on his back and unchal area with a striking "whiplash-marks" configuration (Figure 1a, b) and post-inflammatory hyperpigmentation, typical of flagellate erythema. The eruptions finally faded only after omitting bleomycin, although topical and systemic corticosteroids were prescribed to begin with.

Bleomycin-induced toxicity predominately develops in the lungs and the skin where the bleomycin-inactivating enzyme, bleomycin hydrolase, is absent (5). The exact mechanism of flagellate erythema is currently unclear; however, microtrauma and hyperthermia have been mentioned (2). In addition to bleomycin, it has been reported but rarely associated with dermatomyositis, adult-onset Still's disease and the ingestion of uncooked or half-cooked shiitake mushrooms (4). The reaction is originally considered dose-dependent and usually occurs at total doses more than $200 \mathrm{U}$; however, it has also developed at small dosage as $14 \mathrm{U}$ (2). The duration between administration and the onset of rash varies from 12 to $24 \mathrm{hrs}$ to 6 months. Histology is non-specific but a deep perivascular lymphoeosinophilic infiltrate is noted, which is related to drug-induced pathology (3). The application of topical corticosteroids and oral antihistamine can relieve symptoms, and lesions usually subside 3-4 months later after the cessation of bleomycin, (5) which is necessary to prevent further relapse.
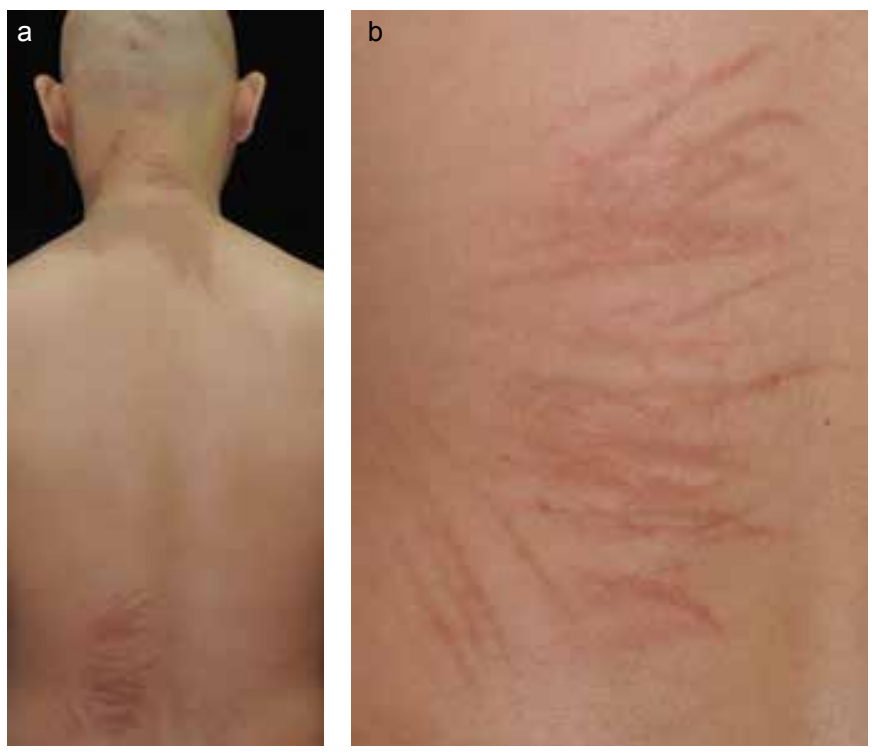

FIG. 1. a, b. Multiple pruritic erythematous linear papules and plaques with post-inflammatory hyperpigmentation on his back and unchal area, typical of flagellate erythema (a). A striking "whiplash-marks" configuration (b).

Ethics Committee Approval: Ethics committee approval was received for this study from the ethics committee of Kaohsiung Veterans General Hospital.

Informed Consent: Written informed consent was obtained from patient who participated in this study.

Peer-review: Externally peer-reviewed.

Author contributions: Concept - CC.L., YY.L.; Design - CH.W.,; Supervision - CH.W.; Resource - YY.L.; Materials - YY.L., QR.W.; Data Collection\&/or Processing - YY.L.; Analysis\&/or Interpretation - QR.W.; Literature Search - CC.L.; Writing - CC.L.; Critical Reviews - CH.W.

Conflict of Interest: No conflict of interest was declared by the authors. 
Financial Disclosure: The authors declared that this study has received no financial support.

\section{REFERENCES}

1. Khaliq W, Antonarakis ES. Flagellate erythema secondary to bleomycin QJM 2012;105:901. [CrossRef]

2. Yamamoto $\mathrm{T}$, Nishioka $\mathrm{K}$. Flagellate erythema. Int $J$ Dermatol 2006;45:627-31. [CrossRef]
3. Simpson RC, Da Forno P, Nagarajan C, Harman KE. A pruritic rash in a patient with Hodgkin lymphoma. Bleomycin-induced flagellate dermatosis. Clin Exp Dermatol 2011;36:680-2. [CrossRef]

4. Adriano AR, Acosta ML, Azulay DR, Quiroz CD, Talarico SR. Shiitake dermatitis: the first case reported in Brazil. An Bras Dermatol 2013;88:417-9. [CrossRef]

5. Todkill D, Taibjee S, Borg A, Gee BC. Flagellate erythema due to bleomycin. Br J Haematol 2008;142:857. [CrossRef] 